\title{
The Triple Qualification examination of the Scottish medical and surgical colleges, 1884-1993
}

\author{
HM Dingwall \\ Honorary Lecturer, School of History and Politics, University of Stirling, Stirling, UK
}

\begin{abstract}
The Triple Qualification (TQ) examination of the three Scottish medical colleges was founded in 1884 in the aftermath of the Medical Act of I858, to offer a medical qualification that would have equal status with that of the universities and other medical schools. Continued efforts to amend the Act had threatened that the universities might dominate basic medical education to the exclusion of the colleges, which opposed this perceived threat to their viability. The TQ proved surprisingly durable and catered for a changing constituency of candidates over the century of its existence, offering a route to medical qualification for individuals from Great Britain and Ireland, the dominions and such diverse groups as exiled Jews from Europe and Rhodesians following independence. This article examines the origins and structure of the examination and assesses the changing candidate profile over the century of its existence.
\end{abstract}

Correspondence to HM Dingwall, School of History and Politics, University of Stirling, Stirling FK9 4LA, UK

tel. $+44(0) 1786467580$

e-mail

helen.dingwall@btinternet.com

KEYWORDS Alternative medical qualification, Scottish Medical Royal Colleges, Triple Qualification

DECLARATION OF INTERESTS No conflict of interests declared.

\section{BACKGROUND}

Medical education is today a highly complex and politicised area, but this is nothing new. All three Scottish medical and surgical colleges owe their origins - at least in part - to politics and patronage. ${ }^{1-4}$ Medical politics in the seventeenth and eighteenth centuries focused on institutional survival and the maintenance of privileges and patronage, but by the Victorian period and the "entry of the state' into matters of health and welfare, ${ }^{5}$ the politics were those of medical reform and the continuation of a process that had begun in the late eighteenth century aimed at regulating a chaotic group of practitioners and preventing the unqualified from practising. ${ }^{6}$ The culmination came, after much acrimonious debate, with the Medical Act of 1858 (2I \& 22 Victoria Cap. 90), ${ }^{3}$ which established the General Medical Council $(\mathrm{GMC})^{7,8}$ and began the process of national standardisation of medical and surgical training, qualification and registration, which led to the establishment of the Triple Qualification (TQ) examination of the three Scottish medical colleges in 1884. Triple Qualification holders were included in a recent study of Scottsh medical students and their subsequent careers," but the present study aims to look at the examination in more detail and over a longer period.

Before 1858 practitioners acquired their qualifications from many sources, including universities, the medical and surgical corporations and, in England, the politically powerful Society of Apothecaries (which had no Scottish counterpart). The Royal College of Surgeons of Edinburgh (RCSEd) instituted a diploma in the 1770s, and in 1815 the various types of diploma which had evolved (for home surgeons and those who intended to serve in the army, navy or on slave ships) were amalgamated into a single Licentiateship examination (LRCSEd). ${ }^{2}$ Fellows of the Royal College of Physicians of Edinburgh (RCPE), established in $168 \mathrm{I}$, were required to possess an MD degree prior to entry. It had also been possible to gain a licentiateship, but this had 'died out entirely' by the midnineteenth century. ${ }^{4}$ The Faculty of Physicians and Surgeons of Glasgow (FPSG; Royal Faculty [RFPSG] from 1911 and Royal College [RCPSG] from 1962) had a surgical licentiateship examination, and medical Fellows were required to have an MD degree..$^{10}$

Although the Edinburgh University Medical School and the Glasgow University Medical School both employed some of the most notable teachers of the time, including the Monro anatomical dynasty in Edinburgh, extra-mural teaching also had a long history. The teaching methods of the Monros were seen increasingly as old-fashioned and no longer appropriate and this contributed to the flourishing of the extra-mural schools. ${ }^{11,12}$ There was by 1858 an established tradition of teaching outside the universities, and this helped to shape medical politics in Scotland after the passing of the Medical Act.

The view that an examination must be undertaken as a mark of preparedness to practise was long established, although it is undeniable that the quality of the examinations was been variable. By the time national politics entered the world of medical education, beginning with the Apothecaries Act of $1815,,^{6,13}$ the belief in examination as proof of knowledge and competence was well established and the Medical Act of 1858 sought to provide a standardised system which would render the proof equally worthy, whatever the entry portal. 
Individuals wishing to practise as military or Poor Law doctors required qualifications in both medicine and surgery, so the RCSEd and RCPE instituted the Double Qualification (DQ) shortly after the Medical Act was passed. Holders of diplomas from both institutions would be entitled to claim dual qualification in medicine and surgery (a separate agreement was concluded between the RCPE and the FPSG). ${ }^{14-16}$

The Scottish medical colleges saw a series of proposals to amend the Medical Act ${ }^{14}$ as a threat to their recognition as licensing bodies, particularly from the universities and from the London College of Physicians. After 1858 there were still some 20 entry portals available to medical students, but when proposals were put forward to establish conjoint examining boards (which were eventually set up in England in 1884), ${ }^{17}$ these were opposed by the Scottish colleges, which believed that they would favour the universities. In 1870 , for example, a memorandum was sent to the House of Lords by the Edinburgh University Senate, claiming inter alia that the university had a 'fully equipped medical school' which was operating 'to higher standards than any of the other award bodies'. ${ }^{18}$ Had this claim found greater support, there would have been a clear danger to the status of the colleges.

The Royal Commission on the Medical Acts was also under way at this time, with the remit of identifying ways to ensure common standards of medical qualification. The Medical Act (Amendment Act) of 1886 stipulated that qualification in both medicine and surgery was required for admission to the Medical Register, in addition to recommending conjoint boards. This meant that there would be an increasing demand for dual qualification. By early 1884 the three Scottish colleges had agreed on a joint medical and surgical qualification that would be wholly within their ambit, with equal entry portal status to that of the university medical schools. ${ }^{14}$

The TQ was approved by the GMC in March 1884 Although the initial arrangement was for a five-year period, the examination survived (with a formal renewal in 1974) until the early 1990s, despite the Goodenough Report of 1944 which effectively channelled basic medical qualification into the universities (and in consequence began the process of transforming the medical corporations into providers of higher medical and surgical training and qualifications)..$^{19}$ In Edinburgh the entry of government into medical training had the further effect of consolidating the ad hoc arrangements of extra-mural lecturers and private anatomy schools into a formal School of Medicine of the Royal Colleges, founded in 1895..$^{20}$ Extra-mural schools were a key element of medical education, and included Anderson's and St Mungo's in Glasgow, Owens College, Manchester (opened in 1873 by the nonconformist business community, later becoming the Victoria University of Manchester), and the Edinburgh Medical College for Women.
TABLE I Single, Double and Triple Qualifications awarded $1884-90$

\begin{tabular}{|c|c|c|c|c|c|c|}
\hline Year & 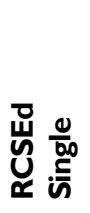 & 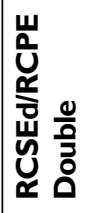 & $\begin{array}{l}\frac{0}{100} \\
\dot{0} \\
u \\
u \\
0 \\
u \\
x\end{array}$ & 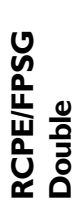 & $\begin{array}{l}\frac{0}{00} \\
\dot{=} \\
0 \\
0 \\
\mathscr{L} \\
0 \\
\frac{1}{4}\end{array}$ & 告 \\
\hline 1884 & 37 & 194 & 204 & 23 & 53 & 10 \\
\hline 1885 & 18 & 103 & 52 & 2 & 9 & 69 \\
\hline 1886 & 9 & 105 & 29 & 2 & $*$ & 100 \\
\hline 1887 & 11 & 5 & 34 & - & & 216 \\
\hline 1888 & 7 & - & 33 & - & & 196 \\
\hline 1889 & 16 & - & 20 & - & & 222 \\
\hline 1890 & 17 & - & 13 & - & & 183 \\
\hline
\end{tabular}

Sources: RCSEd, RCPE and RCPSG Minute Books; RCSEdTQ Schedules.

"No further figures are given for the FPSG Single Licence, although the financial reports for 1887-90 indicate a small income from Single Licence fees. In 1886 the income was some $£ 300$, indicating about 30 candidates, but there is no way of knowing if any of these passed. In subsequent years the income was much smaller, at around $£ 20-30$ per annum. A similar pattern of eclipse of the Single Licence was evident in London. ${ }^{17}$

While the form of the TQ examination remained relatively constant for a century, the nature of the candidate body varied over time, reflecting changes in Britain and internationally, the scourges of racism and war and the consequences of the long process of decolonisation which marked the end of the British Empire. It is fascinating that a product of nineteenthcentury British medical politics, combined with the traditional openness of Scottish institutions, should have come to provide a solution to problems faced by European Jewish emigrés, failed university students and practitioners with non-registrable qualifications from the British dominions or dependent territories.

By the early 1880 s the $D Q$ had eclipsed the single licences of the three Colleges, but following the introduction of the TQ in 1884 , both the DQ and the Single Licence disappeared fairly quickly (Table I).

\section{REGULATIONS}

Curricular requirements for the TQ examination were based around the core subjects of medicine and surgery. By 1930 public health, obstetrics and gynaecology had been added. Towards the end of the period of the TQ multiple choice question (MCQ) papers were introduced in an attempt to modernise the examination following a critical review by the GMC in the mid-1980s.

The required curriculum comprised a number of elements of theoretical and practical study, the successful completion of which had to be signed off on the TQ examination schedule by the relevant teachers. The requirements are given in Table 2 . 
TABLE 2 Curricular requirements of the Triple Qualification

\begin{tabular}{|l|l|}
\hline $\begin{array}{l}\text { Preliminary } \\
\text { examination }\end{array}$ & $\begin{array}{l}\text { Required for GMC registration as } \\
\text { a medical student (or alternative, } \\
\text { such as an arts degree) }\end{array}$ \\
\hline Practical pharmacy & 3 months \\
\hline Hospital experience & At least 24 months ( $\geq 80$ patients) \\
\hline Practical midwifery & At least 6 deliveries \\
\hline Dispensary attendance & 3 months \\
\hline Vaccination certificate & \multicolumn{2}{|l|}{6 months } \\
\hline Anatomy & Two courses of 6 months \\
\hline Practical anatomy & 6 months \\
\hline Chemistry & 3 months \\
\hline $\begin{array}{l}\text { Practical/analytical } \\
\text { chemistry }\end{array}$ & 3 months \\
\hline Materia medica & 6 months \\
\hline Practice of medicine & 6 months, 2nd course of 3 months \\
\hline Clinical medicine & 6 months \\
\hline $\begin{array}{l}\text { Principles and practice } \\
\text { of surgery }\end{array}$ & 6 months, 2nd course of 3 months \\
\hline Clinical surgery & 3 months \\
\hline $\begin{array}{l}\text { Midwifery/diseases of } \\
\text { women and children }\end{array}$ & 3 months \\
\hline Medical jurisprudence & 3 months \\
\hline $\begin{array}{l}\text { Pathological anatomy } \\
\text { or general pathology }\end{array}$ & \\
\hline
\end{tabular}

This was the required curriculum, although many candidates took additional voluntary courses in sanitary science, histology, botany, mental pathology, ophthalmic surgery, diseases of the skin, dental surgery or hygiene and therapeutics. The TQ produced, in addition to hospital doctors, the 'general practitioner' of the time, although the appropriateness of the training for general practice has been called into question with the view that there was too much emphasis on the needs of future specialist practitioners rather than general practitioners. ${ }^{21}$ The expectation was that students would take courses in a recommended sequence aimed at the subjects of the annual examinations, although the order was not enforced rigidly.

The examinations comprised three parts: part one, at the end of the first year of study, on chemistry, practical chemistry, elementary anatomy and histology; part two, at the end of the second year of study, comprising anatomy, physiology, materia medica and pharmacy; and the final examination on the principles and practice of medicine, including therapeutics, medical anatomy and pathology, clinical medicine and the principles and practice of surgery, which comprised surgical anatomy, operative surgery and pathology.

The requirements were modified over the years so that topics which had previously been subsumed within the general headings of medicine or surgery were specified,

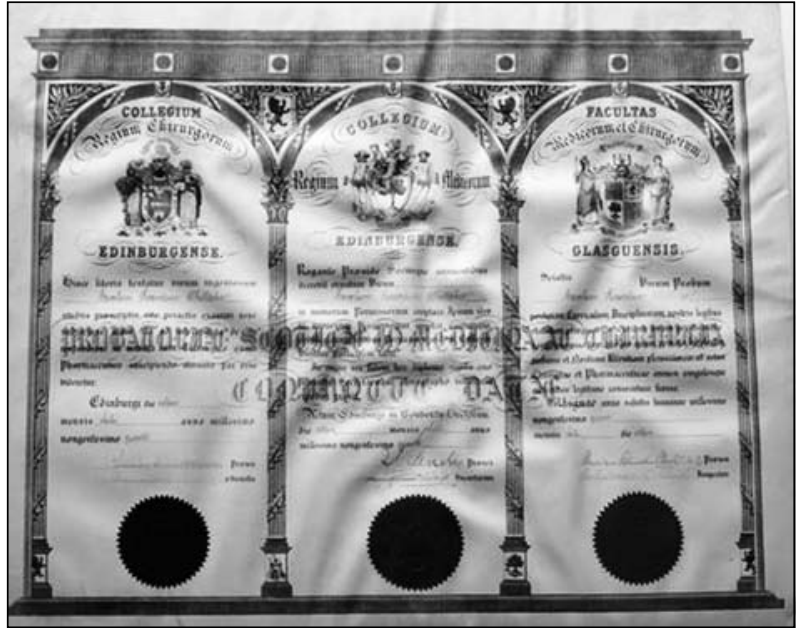

FIGURE I The Triple Qualification certificate awarded to Charles Whittaker (TQ3958) in 1904. Whittaker gained his entire curricular requirements at the School of Medicine of the Royal Colleges in Edinburgh. (Courtesy of RCSEd.)

and new subjects added in line with medical developments. These included anaesthetics, diseases of children, fevers, tuberculosis, insanity, diseases of the eye, diseases of the ear, nose and throat, forensic medicine, orthopaedics and venereal disease (most required one term only). A third professional examination was introduced, covering pathology and materia medica, in order to allow full coverage of the core subjects in the final session. Those who passed received an ornate diploma (Figure I).

Throughout the life of the examination, exceptions to the curricular stipulations were rarely granted, whatever a candidate's individual circumstances. This caused the TQ Board greater problems from the 1930s onwards, when more applicants were presenting with full medical degrees from foreign universities. Most such candidates were obliged to undertake a year's clinical instruction in a British hospital before being admitted to the final examination. In the 1950s and 1960s, for example, following the political upheavals in Hungary, there were many applications from highly qualified individuals who were now stateless refugees, requesting exemption from some parts of the examination. In 1962 a request came from the Clerk of the House of Commons on behalf of a Hungarian friend of his, a qualified doctor 'no longer in his first youth', asking for him to be given credit for his medical experience. No concessions were awarded. Yet part-exemptions were offered to another Hungarian who had qualified at the University of Pécs and had worked on a research project on electroencephalography under Professor JA Simpson in Glasgow. ${ }^{22}$ Another highly qualified individual came from Hungary with a full medical degree and a list of eight publications, but was nonetheless required to undertake a year's clinical study in Britain. ${ }^{23}$

These examples illustrate the ramifications of political upheavals at both the individual and professional level, where medical practitioners, fully qualified in their 
countries of origin, were required to undertake periods of further basic training in Britain before they could practise and thus support themselves financially. The GMC tried on occasion to restrict the numbers of foreign students and practitioners entering Britain, partly because of the relatively large numbers of practitioners. The Scottish institutions had a tradition of openness to foreign students and graduates, which was not always the case in England. The Scottish colleges, for example, resisted attempts by the GMC to enforce a two-year period of clinical training for foreign graduate practitioners rather than the one year required for the $\mathrm{TQ}$, and attempts to restrict numbers of European and American immigrant doctors. ${ }^{24}$ There was also a tradition of practitioners coming to Scotland to qualify but then leaving to practise elsewhere, so that there was perceived to be less danger of the country being flooded by foreign doctors.

\section{CANDIDATES}

Much of the remainder of this paper is based on TQ examination schedules, which survive for successful candidates only, and are complete from 1887, commencing with TQ218. The RCSEd provided an administrative centre for the TQ, and the schedules are housed within its archives. A full list of Licentiates was compiled by the late AHB Masson, and this has been of great value. Individuals qualifying after 1920 have been identified by initials only. The schedules contained details of age, place of birth, date of registration as a medical student, address at application for the examination and the signed curriculum requirements, with dates for each course taken and the names of the relevant teachers. Table 3 demonstrates the numbers of TQ passes and how these changed over the period. These figures demonstrate clear trends, particularly in relation to the percentages of female candidates, with a dramatic increase during and after the Second World War and a subsequent dip in numbers but not to pre-war levels. In the 1970s and 1980s overall numbers rose from the dip in the 1960s, primarily because of the influx of qualified doctors from Southern Rhodesia (Zimbabwe), but dwindled significantly thereafter. It is clear from the low figures in the 1990s that the exam could not survive independently.

The TQ made a fairly significant contribution to the total number of medical practitioners in Britain in its first halfcentury. A five-yearly survey of letter A surnames in the Medical Registers shows that between 1890 and 1945 an average of some $7 \%$ of registered practitioners possessed the Scottish TQ, the peak coming in 1905, when more than $9 \%$ were in this category. Given the wide variety of entry portals, this is a not insignificant figure. After the Goodenough Report ${ }^{19}$ the universities became the dominant entry portal for medical qualification relatively quickly.

The register of TQ passes shows that the first successful candidate in 1884 was George Armstrong (TQI). He is
TABLE 3 Numbers of TQ passes by decade

\begin{tabular}{|l|l|l|l|}
\hline Years & Male (\%) & Female (\%) & Total \\
\hline $1884-9$ & $819(96.5)$ & $30(3.5)$ & 849 \\
\hline $1890-9$ & $2,136(93.3)$ & $157(6.8)$ & 2,293 \\
\hline $1900-9$ & $1,095(91.9)$ & $97(8.1)$ & 1,192 \\
\hline $1910-9$ & $703(95.9)$ & $30(4.1)$ & 733 \\
\hline $1920-9$ & $987(92.6)$ & $79(7.4)$ & 1,066 \\
\hline $1930-9$ & $1,145(91.2)$ & $111(8.8)$ & 1,256 \\
\hline $1940-9$ & $1,149(88.4)$ & $152(11.6)$ & 1,301 \\
\hline $1950-9$ & $426(78.0)$ & $120(22.0)$ & 546 \\
\hline $1960-9$ & $110(82.8)$ & $23(17.2)$ & 133 \\
\hline $1970-9$ & $208(80.7)$ & $50(19.3)$ & 258 \\
\hline $1980-9$ & $491(83.1)$ & $100(16.9)$ & 591 \\
\hline $1990-3$ & $22(78.5)$ & $6(21.5)$ & 28 \\
\hline Total & $9,291(90.7)$ & $955(9.3)$ & 10,246 \\
\hline
\end{tabular}

Source: RCSEd and RCPSG Minute Books and RCSEdTQ Schedules. It is not possible to give reliable figures for total numbers of candidates - and therefore percentages of failures for the whole period. Extant figures for $1890-9$ give a total of 2, I 32 passes and 2,808 failures, a pass rate of some $48 \%$, although these may not be precise figures. The final group in 1993 comprised 33 candidates, of whom seven passed, a pass rate of $21 \%$, although it is difficult to compare two widely differing totals.

noted in the 1905 and 1915 Medical Registers and Medical Directories as living in London, although there is no indication as to whether he was still practising. The first surviving full schedule is that of John Rogerson (TQ2 18), born in Lochrutton near Dumfries in 1859. He took the preliminary examination at Glasgow University in 1880, and from that point pursued his studies at Dumfries and Galloway Royal Infirmary, the Andersonian Dispensary, Glasgow Royal Infirmary, Glasgow University and Anderson's College. This was a typical progression, the candidate gaining the segments of the required curriculum in a number of institutions. The combination of intra- and extramural training was very common during the first few decades of this examination, undertaken by around $25 \%$ of candidates. Rogerson seems to have passed at his first attempt in 1887 as evidenced by the absence of any 'resit slips' in the documentation. Many candidates, however, had multiple attempts before succeeding.

A quarter of the 214 candidates who passed the final examination in 1900 had taken a multi-location educational route, and came from all parts of Britain and Ireland, from Canada, India, Ceylon (Sri Lanka) and Argentina. Crowther and Dupree demonstrated a similar pattern among the matriculated university students in their cohort. ${ }^{9}$ In 1920 there were only 57 successful candidates, due in all probability to the effects of the First World War on study and numbers. Nine of these were female, and 12 had followed a mixed-location curriculum, though $65 \%$ of the total had studied wholly in Edinburgh or Glasgow. Foreign candidates came from Ceylon, Russia, India and the USA. When the School of 
Medicine of the Royal Colleges closed in 1945, and the extra-mural schools in Glasgow were absorbed by the university, single-location study became the norm. Examinations for college licences were reputed to be easier than university examinations, but this has yet to be proved, and the failure rate of the TQ and other licences was similar to that in the universities.'

Perhaps one of the most significant periods in terms of general context is the 1930s. The enforced migration of Jews from many parts of Europe is mirrored in the dramatic increase in the numbers of TQ candidates possessing Jewish names and European medical degrees. For them the TQ was the only means of obtaining a qualification registrable in Britain. A number of candidates had also changed their names - from Rosenberg to Rose or Blumenkranz to Barret. From 1933 to 1938 almost $25 \%$ of the successful candidates were of European Jewish origin, demonstrating the clear benefits of the TQ to that group. They included a number of senior physicians, such as Professor JP Plesch (TQ6895), who had been appointed Professor of Internal Medicine at the University of Berlin in 1917 but was still required to complete the statutory period of clinical experience in Britain at the age of 56. Following the wave of Jewish migrants to Scotland in the 1880 s the numbers entering the medical profession grew steadily and this, coupled with the fact that the Scottish TQ required foreign graduates to undertake only one year's clinical study as opposed to two in England, made Scotland the natural location of choice for the displaced Jewish physicians and medical students. This is demonstrated clearly in Collins' important analysis of Jewish medical practitioners. ${ }^{24}$

During the same period, Jews in America were encountering significant barriers to their entry to the medical schools and medical profession, and many Jewish-American medical students travelled to Scotland, where the universities imposed no religious barriers and where there were opportunities to enter the extra-mural schools and complete their training. The GMC had urged caution in the large-scale acceptance of American students, but the Scottish institutions resisted these moves and remained much more open to American students than their English counterparts. In 1938, for example, 343 of the 456 American graduates from the various British portals gained their qualification in Scotland. ${ }^{24}$

During the late 1940s and early 1950s the candidates included considerable numbers of British students whose studies had been interrupted by war service, while from the early 1960s the vast majority of candidates hailed from overseas. In January 1965, for example, candidates came from Japan, Portugal, France, Germany, Italy, Israel, Iran, India, China and Egypt. It is clear that by the late 1960s re-qualification was the primary function of the TQ, and it was perhaps fortunate in economic terms for the Colleges that this refocusing could take place.
The 1970s saw the TQ in considerable economic difficulty, but the Examination Board expressed a strong wish to continue, although it was decided in 1978 not to admit undergraduate candidates from medical schools outside the British Isles because of the difficulties and cost involved in assessing teaching standards in many locations worldwide. ${ }^{25}$ Meetings of the TQ Board at that time were concerned with determining the quality of basic medical training at foreign universities and the eligibility of candidates from these locations to be entered directly for the final TQ examination or for an earlier part. Economic viability in the later 1970s and 1980s was assisted by the influx of large numbers of Southern Rhodesians following the unilateral declaration of independence in 1965, but thereafter numbers dwindled significantly. All of the 33 applicants for the final diet of the examination in 1993 had medical degrees from foreign universities. Seven candidates passed (21\%), 19 failed and the rest withdrew, with one absentee.

It is apparent that throughout the life of the TQ - although rather less towards the end - a number of candidates took their entire curriculum at a single university but had not graduated there. One conclusion is that these candidates had failed their university finals (although there were a few instances of TQ holders gaining a medical degree at the same time). ${ }^{25}$ One example is that of Eric Hutchison (TQ4699), an Australian who matriculated at the University of Sydney in 1901 and gained all of his curricular requirements there before passing the TQ in 1910. This trend was not confined to foreign candidates, however, and a small number of home students also presented after a full university course, possibly in order to achieve an 'easier' qualification which would allow the candidate to practise before sitting the university examinations. These included one candidate in 1969 (well beyond the period when multiple basic qualifications were taken), who had completed the full medical curriculum at Newcastle University but had failed the final examinations. ${ }^{26}$

One conclusion from this analysis is that the examination provided an entry portal for three groups of candidates: those who fulfilled the curriculum by any approved route, those who had studied wholly at a university but failed their final examinations and pre-qualified applicants who required a registrable qualification.

\section{A FEW NOTABLE INDIVIDUALS}

The TQ not only provided a practical solution for many candidates, but also offered a medical qualification to individuals who would subsequently achieve prominence, or who were somewhat 'out of the ordinary'. One of the most notable was Elsie Inglis (TQ 1369), who qualified in 1892 , the year in which women were finally admitted to study at Scottish universities (Figure 2). Her final examination schedule shows that she had achieved the required curriculum by taking the preliminary 


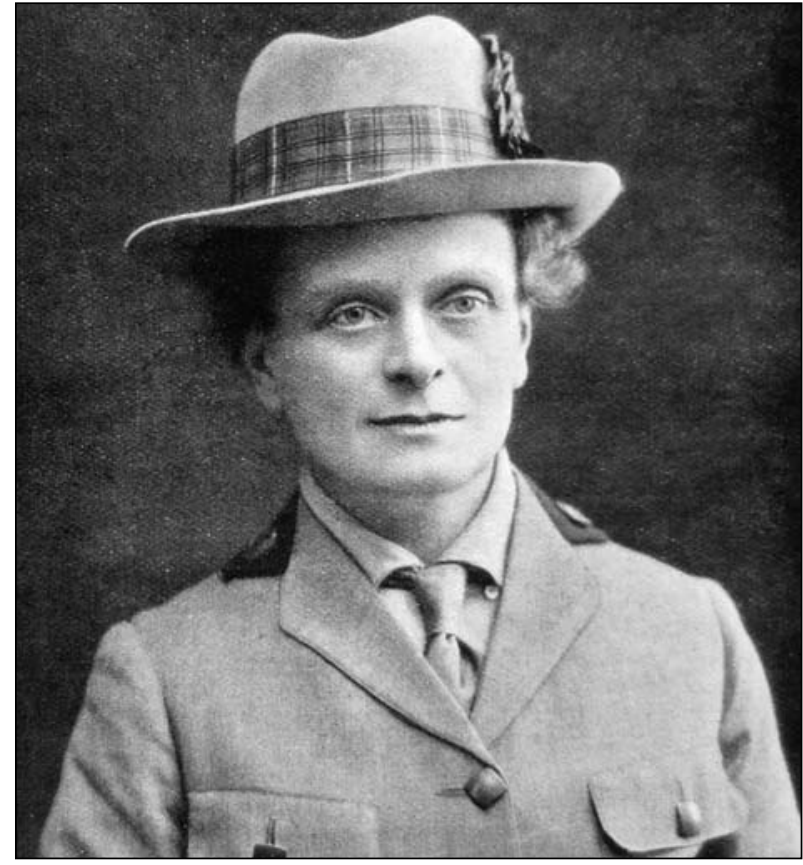

FIGURE 2 Elsie Inglis, who gained the TQ in 1892. (From: Balfour F. Dr Elsie Inglis. London: Hodder and Stoughton; 1918.)

examination of the Educational Institute of Scotland, followed by courses at the Edinburgh School of Medicine for Women together with practical experience at Leith Hospital, Glasgow Royal Infirmary and the Glasgow Royal Infirmary Dispensary. She gained non-compulsory experience at the Cowgate Dispensary, the Edinburgh Maternity and Sick Children's Hospitals and St Mungo's College, Glasgow. Among her teachers was Henry Littlejohn, more famous in his role as Edinburgh's first Medical Officer of Health. ${ }^{27-30}$ The TQ, which was open to women from the start, was of considerable significance to her medical education and subsequent career, as was the presence of the redoubtable Sophia Jex-Blake's School of Medicine for Women - although Inglis was involved in setting up a rival school of medicine following disagreement about Jex-Blake's methods. ${ }^{31}$

The TQ, as mentioned, offered a significant lifeline to highly qualified and experienced individuals from abroad who were for some reason forced to leave their homeland. Some had occupied high-status posts before coming to the UK. One example is Dr Benjamin Alexandrovitsch Belilovsky (TQ5247) in 1920 (Figure 3). $\mathrm{He}$ had qualified at the University of Kiev, specialised in 'occulism and ophthalmology' and had acted as liaison officer between the British and Russian medical staffs during the occupation of Arkhangelsk at a time when Inglis was also there. A further Edinburgh link was that Belilovsky's application to sit the TQ was signed by JD Comrie, who wrote the first full history of medicine in Scotland and who had been consultant to the British forces in North Russia. ${ }^{32}$ The TQ Board made few exceptions to the prescribed curriculum, and Belilovsky was instructed to take a vaccination course despite the

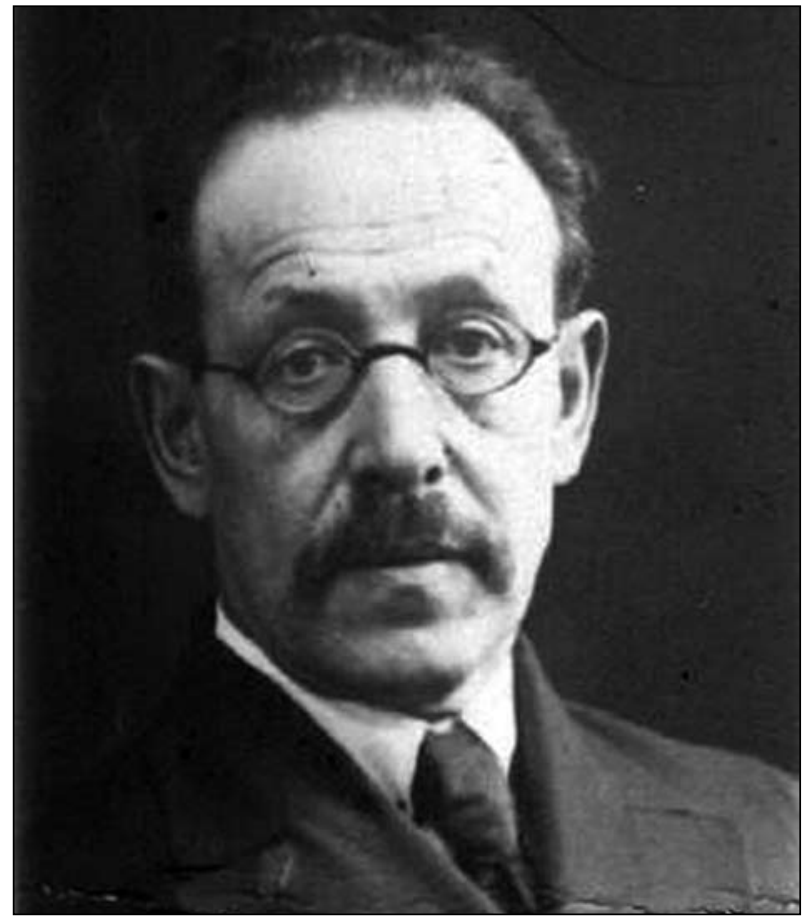

FIGURE 3 Benjamin Alexandrovitsch Belilovsky who gained the TQ in 1920. (Photograph attached to his letter of application, reproduced courtesy of RCSEd.)

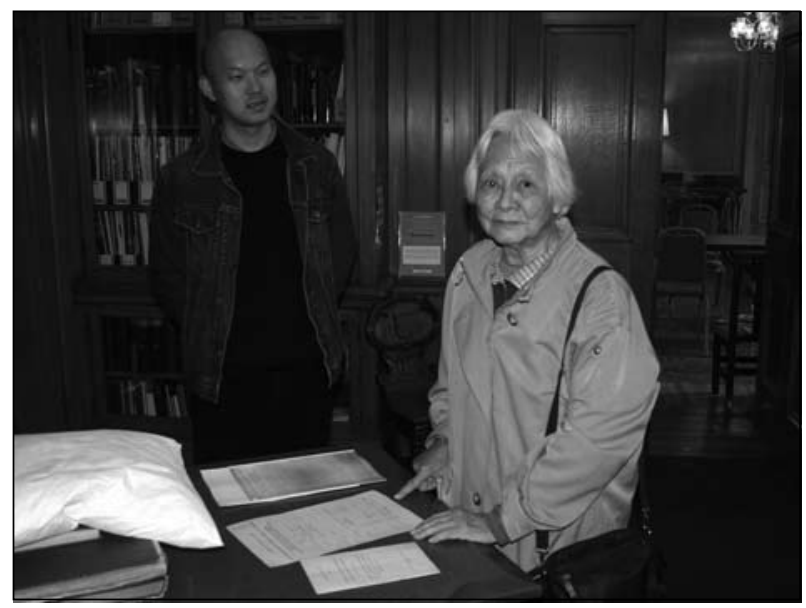

FIGURE 4 Dr Lim Phaik-Lin (right), photographed in 2007, who gained the TQ in 1946. (Courtesy of RCSEd.)

fact that he had managed the Institute of Vaccination at Astrakhan from 1907-II. Belilovsky was 54 years of age when he took the TQ examination and clearly a very experienced doctor, but there was little room for flexibility in the acceptance of unusual candidates.

More recently, a TQ holder from the 1940s visited the RCSEd (Figure 4). Dr Lim Phaik-Lin (TQ8948) travelled to Scotland by boat from Malaysia in 1940 and undertook her full period of medical studies in Edinburgh, passing her final TQ examination in 1946. Her training schedule confirms the ongoing activities of the School of Medicine of the Royal Colleges (before it closed in 1945), as she took courses there in pathology, pharmacology, forensic medicine, public health, midwifery, gynaecology, surgery 
and operative surgery, medicine, mental diseases, eye, ear, nose and throat, dermatology, paediatrics, tuberculosis and venereal diseases - the rest of her curricular requirements coming from Edinburgh University, the Edinburgh Royal Infirmary and the Marshall Street Dispensary. Following qualification, Dr Lim gained a Diploma in Tropical Medicine and Hygiene, and after posts in various UK hospitals she worked in Malaysia as Lady Medical Officer in Penang General Hospital, and in Brunei. She died in 2009.

\section{EARLY OPPORTUNITIES FOR WOMEN}

Perhaps unexpectedly, women were admitted to the TQ from the start, and were thus afforded an opportunity which was not yet available to them at the universities. The first successful female candidate was Alice Ker (TQ I53), who gained her diploma on 30 July 1886. She had matriculated at Edinburgh University in 1872, but when the University Court appealed successfully against Jex-Blake's legal action on behalf of female students, studied subsequently in London, Ireland, the USA and Switzerland. She was admitted to the Medical Register in 1879 and returned to Edinburgh to take the TQ in I886, as this offered her a surgical qualification..$^{9,33,34}$ Ker's subsequent career was varied, and included both hospital work and general practice as well as publishing two books, ${ }^{35,36}$ raising a family and participating in the suffrage movement.

The numbers of female candidates remained relatively modest but not insignificant (see Table 3) and rose considerably during and after the Second World War, and then in the 1970s and 1980s with the influx of Southern Rhodesians. In October 1888 there were five female passes, compared with 65 males, and in August 1895 the 68 successful candidates included 13 females. The TQ schedules of these candidates were signed off by some of the most famous medical people of the day. Jean Robertson (TQ1362, 1892) had her entire curriculum validated by the bold signature of Jex-Blake. She had also been taught by Charles Cathcart, co-founder of the School of Medicine of the Royal Colleges in 1895, and Henry Littlejohn. ${ }^{2}$ In the same year, Anne Augusta Wilson (TQI254), from Baltimore, USA, studied at the London School of Medicine for Women and the Royal Free Hospital, and was taught by Elizabeth Garrett Anderson, another pioneer in female medical education. ${ }^{37}$ Rather less widely known than Inglis was her friend Jessie MacGregor (TQ 1352). MacGregor lectured in histology at the School of Medicine of the Royal Colleges in Edinburgh as well as practising medicine in partnership with Inglis before emigrating to America in 1905. ${ }^{38}$

The need for separate women's medical colleges disappeared once female students were accepted by the universities. The proportion of female candidates increased over the period, rising to just under a quarter, even in the 1980s, which does seem rather low given that nowadays female medical students are in the majority. ${ }^{39}$ There seems little doubt that immediate acceptance of female candidates was a positive feature of the TQ, and although career opportunities for female doctors were limited in the earlier decades this examination at least gave them a chance to practise medicine until the universities were open to female students. ${ }^{40}$

\section{CO-OPERATION AND SOME UNION}

By the late 1960s joint approaches by all the British Non-University Licensing Boards had been agreed in terms of the re-qualification of foreign candidates so there was an element of inter-board co-operation. Despite the strong desire for the $\mathrm{TQ}$ to remain independent, a Standing Liaison Committee was appointed to oversee co-operation. ${ }^{41}$ Candidates with 12 months' clinical experience in the UK, together with temporary registration under the Professional and Linguistic Assessments Board's regulations and favourable consultants' references, would be admitted direct to the final examination. Candidates who had worked for more than five years in the UK could be admitted without a consultant reference. There were also moves to exempt foreign candidates from forensic medicine and public health examinations as they had normally taken these subjects earlier in their medical curriculum than home candidates (of whom there were few by that stage).

During the 1980s it was agreed that, because of larger numbers and many poor quality candidates, all applicants would be required to pass the Professional and Linguistic Assessments Board test. A GMC inspection in 1985 had noted insufficiencies and that the TQ exam was 'undoubtedly old-fashioned', and changes introduced subsequently included MCQ tests and an alteration of the format of clinical and written examinations. ${ }^{42}$

The last diet of the TQ examination was held in 1993, but that was not completely the end, as from 1994 the Non-University Licensing Boards combined to form the United Examining Board (UEB), which would operate a single examination from 1994. Candidates would be awarded the licence of the examining board where they took the examination. A final twist to the TQ saga was that during its final, faltering years there was a vigorous campaign to keep the UEB examinations going as a means of catering for medically qualified asylum seekers - this very redolent of the political events of the 1930s, 1950s and 1970s/80s which had shaped the candidate profile previously. There was a flurry of correspondence to the medical journals in favour, ${ }^{43-45}$ but as medical schools gradually withdrew their facilities from UEB candidates, and the UEB agreed eventually that its candidates should be examined by the universities and not separately by the board, the death knell was sounded. The board was dissolved in 2007, bringing a final end to the TQ and an ultimate concession to the universities, which the founders of the TQ had always feared. 


\section{CONCLUSION}

It is clear that an examination which was born out of short-term political expediency, but also because of the traditional openness of the Scottish institutions to foreign medical students and graduates in peacetime as well as during periods of conflict, became an important - and often the only - means by which disadvantaged individuals could enter the medical profession in Britain.

At the start it was one of a wide choice of entry portals; latterly it became a means to an end for a few individuals. At the start it covered very much the same curriculum as the universities; by the end its form and structure were deemed no longer fit for purpose, although accusations that TQ examinations were easier than those of other institutions cannot be substantiated definitively. It was,

\section{REFERENCES}

I Craig WS. The history of the Royal College of Physicians of Edinburgh Oxford: Blackwell; 1976.

2 Dingwall HM. A famous and flourishing society. The history of the Royal College of Surgeons of Edinburgh, 1505-2005. Edinburgh: Edinburgh University Press; 2005.

3 Geyer-Kordesch J, Macdonald F. Physicians and surgeons in Glasgow. The history of the Royal College of Physicians and Surgeons of Glasgow, 1599-1858. London: Hambledon; 1999.

4 McCrae M. Physicians and society. Edinburgh: John Donald; 2007.

5 Finlayson G. Citizen, state and social welfare in Britain 1839-1900. Oxford: Clarendon Press; 1994.

6 Loudon I. Medical care and the general practitioner 1750-1850 Oxford: Clarendon Press; 1986. p. 133-5I.

7 Heseltine M. The early history of the General Medical Council (18581886). London: Medical Press; 1949.

8 Pyke-Lees M. Centenary of the General Medical Council 1858-1958. The history and present work of the Council. London: GMC; 1958.

9 Crowther MA, Dupree MW. Medical lives in the age of surgical revolution. Cambridge: Cambridge University Press; 2007.

10 Duncan A. Memorials of the Faculty of Physicians and Surgeons of Glasgow. Glasgow: Maclehose; 1896. p. 99.

II Lawrence C. The Edinburgh Medical School and the end of the 'Old Thing' 1790-1830. Hist Universities 1988; 7:259-86.

12 Dingwall HM. The importance of being Edinburgh. The rise and fall of the Edinburgh Medical School in the eighteenth century. In: Grell OP, Cunningham A, Arrizabalaga J, editors. Centres of medical excellence? Medical travel and education in Europe, 1500-1789. Farnham: Ashgate; 2010. p. 305-24.

$1355 \mathrm{Geo}$ III Cl94.

14 Hull A, Geyer-Kordesch J. The shaping of the medical profession. The history of the Royal College of Physicians and Surgeons of Glasgow, 1858-1999. London: Clarendon; 1999. p. 8-17.

15 Nutton V, Porter R, editors. The history of medical education in Britain. Amsterdam: Rodopi; 1995.

16 Poynter FN, editor. The evolution of medical education in Britain. London: Pitman Medical; 1966.

17 Cooke AM. A history of the Royal College of Physicians of London. Vol. 3. Oxford: Clarendon; 1972. p. 835-72.

18 Edinburgh University Library (EUL) Da31.5, Minutes of the Senatus Academicus, 24 June 1870, 14 June 1872.

19 Goodenough W. Report of the Inter-Departmental Committee on Medical Education [Goodenough Report]. London: HMSO; 1944.

20 Guthrie DJ. Extramural medical education and the School of Medicine of the Royal Colleges. Edinburgh: Livingstone; 1965.

21 Digby A. The evolution of the British general practice 1858-1948. Oxford: Oxford University Press; 1999. p. 59-63. however, fit for the needs of a changing constituency of candidates for more than a century and must be regarded as a significant part of the history of medical education in Scotland and in the wider context. The changing candidate profile demonstrates that despite decolonisation, Britain attracted many aspiring doctors from former colonies and dependent territories, and provided a safe haven for European political exiles.The minds of those who negotiated the original TQ agreement were on other things. It is impossible to know whether they would have been pleased with the unexpected results of their creation.

Acknowledgements I am grateful to the library and archive staffs of the RCSEd, RCPE and RCPSG. Thanks are also due to Sui-Fei Lim for information about her mother's career, to the late AHB Masson for compiling a list of TQ holders and to my referees for helpful suggestions.

22 RCSEd, RSFI, letter dated 4 July 1967 from Professor Simpson.

23 Czigany M. 'Just like other students'. The reception of the 1956 Hungarian refugee students in Britain. Newcastle upon Tyne: Cambridge Scholars; 2009.

24 Collins K. Go and learn. The international story of Jews and medicine in Scotland. Aberdeen:Aberdeen University Press; 1988. p. 133-58.

25 RCSEd, TQ minutes, 25 May 1978.

26 RCSEd,TQ minutes, 24 July 1969.

27 RCSEd,TQ schedules No. 1369; 1892

28 Kaufman MH. Medical teaching in Edinburgh during the eighteenth and nineteenth centuries. Edinburgh: Royal College of Surgeons of Edinburgh; 2003.

29 Dyhouse C. No distinction of sex? Women in British universities 1870-1939. London: UCL Press; 1995.

30 Gordon WM. The right of women to graduate in medicine Scottish judicial attitudes in the nineteenth century.J Legal History 1984: 52:136-51. doi: 10.1080/0I440368408530802

31 Roberts S. Sophia Jex-Blake. A woman pioneer in nineteenth century medical reform. London: Routledge; 1993.

32 RCSEd, TQ schedules No. 5427.

33 Bonner TN. To the ends of the earth. Women's search for education in medicine. Cambridge, Mass: Harvard University Press; 1995.

34 Cowman K. Alice Jane Shannan Stewart Ker (1853-1943), doctor and suffragette. In: Oxford Dictionary of National Biography. Oxford: Oxford University Press; 2004-10.

$35 \mathrm{Ker}$ A. Manchester domestic economy classes. Lectures to women. No I-3. Manchester: J Heywood; 1884.

36 Ker A. Motherhood: a book for every woman. Manchester:J Heywood; 1891.

37 Manton J. Elizabeth Garrett Anderson. New York: Dutton; 1965.

38 Ewan A, Innes S, Reynolds S, editors. The biographical dictionary of Scottish women from the earliest times to 2004. Edinburgh: Edinburgh University Press; 2006. p. 178.

39 Smith R. Women doctors will outnumber men within a decade. Daily Telegraph, 3 June 2009.

40 Alexander W. Early Glasgow women medical graduates. In: Gordon E, Breitenbach E, editors. The world is ill divided; women's work in Scotland in the nineteenth and early twentieth centuries. Edinburgh: Edinburgh University Press; 1990. p. 70-94.

4 I RCSEd, TQ minutes, 30 january 1969.

42 RCSEd, TQ minutes, 7 March, 1986.

43 Gibberd FB. GMC must not recommend abolition of United Examining Board's examination. BMJ 1998; 316:1386.

44 Beedham T. Helping refugee doctors. BMJ 2000; 320:887-8. doi: I0.I I36/bmj.320.7239.887

45 Eastwood JB, Fiennes AG, Cappuccio FP et al. Registering refugee and asylum-seeking doctors. Lancet 1998; 352:647-8. doi:10.10161 SOI40-6736(98)05357-4 